\title{
MAPLE SYRUP URINE DISEASE
}

\author{
BY \\ A. D. PATRICK \\ From the Institute of Child Health, The Hospital for Sick Children, Great Ormond Street, London
}

(RECEIVED FOR PUBLICATION AUGUST 3, 1960)

A familial syndrome characterized by gross mental retardation, a urine odour resembling maple syrup, and a short fatal course, was first described by Menkes, Hurst and Craig (1954). Two similar cases have since been reported (Westall, Dancis and Miller, 1957; Dancis, Levitz, Miller and Westall, 1959; Mackenzie and Woolf, 1959), in which markedly raised levels of leucire, isoleucine and valine were found in urine and plasma. Analysis also revealed high concentrations of the $\alpha$-keto acids derived from these branched-chain amino acids by transamination (Menkes, 1959).

These abnormalities could result from a defect in the further degradation of the keto acids, for which the most probable normal pathway involves a common mechanism of oxidative decarboxylation (Coon, Robinson and Bachhawat, 1955; Fig. 1), and recent work has sought to substantiate this inference.

A study of one of the cases mentioned above has been summarized recently by Dancis, Levitz and Westall (1960). The further biochemical investigation of the other case was undertaken at this hospital, and the results obtained are presented in this report.

\section{Case History}

A full report on first admission of the child to The Hospital for Sick Children has been given by Mackenzie and Woolf (1959). Dietary trials carried out at University College Hospital are the subject of the previous paper in this iss:te (Dent and Westall, 1961).

The patient, a girl, was the only child of healthy, unrelated parents, with no family history of mental deficiency. She appeared normal at birth, but stopped sucking at 1 week, and had to be fed by tube.

On admission to The Hospital for Sick Children, aged 4 months, she was severely mentally retarded, and some jerking of the limbs was noted. The urine possessed a persistent odour resembling burnt sugar, and analyses of urine and plasma for amino and keto acids confirmed the suspected diagnosis of maple syrup urine disease. A diet containing glycine as the sole amino acid was tried, but no improvement in the clinical or biochemical findings was observed. When 8 months old she was transferred to the metabolic unit of University College
Hospital, for further investigation of restricted diets, and from there was admitted to Botley's Park Hospital, where she died on August 23, 1959, aged 15 months. The post-mortem findings are to be published by Crome, Dutton and Ross (1961).

\section{Materials and Methods}

A 24-hour collection of urine from the patient at 8 months of age had been stored at $-25^{\circ} \mathrm{C}$. for nine months. Post-mortem specimens of liver, kidney and brain were frozen immediately and kept at $-25^{\circ} \mathrm{C}$. Control specimens from a patient of about the same age, who died from congenital heart disease, were treated in the same manner.

Chromatography. Amino acid chromatography was carried out in the usual way on Whatman No. 1 paper, using n-butanol-acetic acid-water (12:3:5 by vol.) as solvent system. Tissue incubation media were deproteinized with ethanol, and concentrated to small volume for analysis. These solutions were analysed also for metabolic intermediary acids (Lugg and Overell, 1948). For the detection of coenzyme A derivatives (Stadtman, 1952), media were deproteinized by an equal volume of ethanol adjusted to $p \mathrm{H} 4 \cdot 5$ with $0 \cdot 1 \mathrm{~N}$ sodium acetate buffer.

Urinary keto acids were characterized as the 2:4dinitrophenylhydrazones in a butanol-ethanol-ammonia solvent (El Hawary and Thompson, 1953). Trichloracetic acid filtrates of tissue media were analysed similarly. The $\alpha$-ketoisocaproic acid used as a standard was obtained from the California Corporation for Biochemical Research, Los Angeles, and purified by recrystallization of the barium salt from aqueous acetone.

An ether-soluble fraction of acidified urine was obtained by continuous extraction for 12 hours. After removal of ether, the residual oil was dissolved in dilute ammonia, and chromatographed on Whatman No. 2 paper, with a solvent system, n-butanol-n-propanol$0.1 \mathrm{~N}$ ammonia (2:1:1 by vol.). Ammonium salts produced red spots when sprayed with diazotized p-nitroaniline and alkali (Whitfield, 1960). Further information on the identity of the spots was obtained by using 2:4-dinitrophenylhydrazine and ferric chloridephenol as spray reagents.

Identification of $\alpha$-Hydroxy Acids. Some conversion of urinary $\alpha$-hydroxy acids to the corresponding keto 
acids was obtained by careful oxidation with Fenton's reagent. Urine $(2 \mathrm{ml}$.) was diluted to $5 \mathrm{ml}$. with water, and cooled to $0^{\circ} \mathrm{C}$. Ferrous sulphate solution $(0.1 \mathrm{ml}$. of $0.001 \mathrm{M})$ and hydrogen peroxide $(0.1 \mathrm{ml}$. of $0.2 \%)$ were added, and the mixture kept at $0^{\circ} \mathrm{C}$. for six hours. While still cold, $0.4 \mathrm{ml}$. of a saturated solution of 2:4-dinitrophenylhydrazine in $2 \mathrm{~N} \mathrm{HCl}$ was added, and the mixture allowed to warm to room temperature. Extraction and chromatography of the resulting hydrazones was carried out as before.

Areas of paper occupied by individual spots were cut from a preparative chromatogram, and disintegrated in dilute acetic acid. The amino acids derived from these hydrazones by electrolytic reduction (Smith, 1958) were then identified by chromatography.

Tissue Experiments. Tissue homogenates were prepared in the appropriate ice-cold solutions, using an all-glass homogenizer of the Potter type.

Transamination. Incubation mixtures contained Lleucine $(0.01 \mathrm{M})$, pyruvate or $\alpha$-ketoglutarate as the sodium salts (0.01 M), and $4 \mathrm{ml}$. of a $10 \%$ tissue homogenate in $0 \cdot 1 \mathrm{M}$ phosphate buffer, $p \mathrm{H} 7 \cdot 4$, in a total volume of $10 \mathrm{ml}$. The tests were run anaerobically at $37^{\circ} \mathrm{C}$. Transamination was followed by periodic analysis for amino and keto acids.

Oxidative Decarboxylation. Tests for the anaerobic production of carbon dioxide were carried out by the standard Warburg method, using a medium of the following composition (concentrations expressed in $\mu$ moles): potassium phosphate, $\mathrm{pH} 7 \cdot 4,200$; magnesium sulphate, $2 \cdot 5$; cysteine, 10 ; diphosphopyridine nucleotide (DPN), 0.2; keto acid, $\mathrm{K}$ salt, 50; coenzyme A, 10; thiamine diphosphate, $\mathbf{0 . 2}$; adenosine diphosphate (ADP), 10. Tissue slices, or a $10 \%$ homogenate in $0.05 \mathrm{M}$ phosphate, $p \mathrm{H} 7.4(1 \mathrm{ml}$.), were used in a final volume of $2 \mathrm{ml}$. Incubation temperature was $37^{\circ} \mathrm{C}$.

\section{Results}

The characteristically raised levels of leucine, isoleucine and valine, and of the corresponding keto acids were the most prominent features of urine analysis. The 24-hour excretions of leucine and $\alpha$-ketoisocaproate were approximately $25 \mathrm{mg}$. and $65 \mathrm{mg}$., respectively. The keto acid pattern also showed an abnormally high level of $\alpha$-ketoglutarate.

The presence of $\alpha$-hydroxy acids in the urine was indicated by comparison of its reaction with $2: 4-$ dinitrophenylhydrazine before and after oxidation with Fenton's reagent. The reaction was greatly increased after oxidation, the component showing greatest change $\left(R_{F} \quad 0.82\right)$ coinciding with the dinitrophenylhydrazone of $\alpha$-ketoisocaproic acid. This identity, and the presence of the superimposed hydrazone of $\alpha$-keto- $\beta$-methylvaleric acid, was confirmed by the formation of increased amounts of leucine and isoleucine by electrolytic reduction.
From these results it may be concluded that the urine contained $\alpha$-hydroxy-isocaproic and $\alpha$-hydroxy$\beta$-methylvaleric acids, the derivatives of leucine and isoleucine, respectively. The acid corresponding to valine, namely, $\alpha$-hydroxy-isovaleric acid, could not be detected by these methods.

Further confirmation of the identity of the urinary acids was derived from chromatography of the ether extractives. Two main components were coloured red by the diazo reagent, and each could be further resolved into two by the use of alternative spray reagents. The faster-moving areas $\left(R_{F} 0 \cdot 50\right.$ and $0 \cdot 38$ ) reacted strongly with dinitrophenylhydrazine, and coincided with $\alpha$-ketoisocaproic and $\alpha$-ketoisovaleric acids, respectively. The slowermoving areas $\left(R_{F} 0.46\right.$ and 0.35$)$ reacted for $\alpha$ hydroxy acids in giving a yellow colour with a phenol-ferric chloride spray, and coincided with $\alpha$-hydroxy-isocaproic and $\alpha$-hydroxy-isovaleric acids, respectively.

The oil derived from the ether extract also possessed much of the maple syrup odour, and this was found to be concentrated in two spots $\left(R_{F} 0.56\right.$ and 0.42 ) on the chromatograms. These constituents were completely separated from the abovementioned acids, and were stained yellow by the diazo reagent, thereby differing from carboxylic compounds. Immediate reaction also occurred with dinitrophenylhydrazine and with ammoniacal silver nitrate. Some separation of the 'maple syrup substances' was obtained by gently warming the oil, to which a few drops of water had been added. Colourless needle crystals were deposited rapidly in the neck of the flask, and were shown to contain the 'maple syrup substance' of $R_{F} 0.56$, together with some $\alpha$-hydroxy-isovaleric acid, by chromatography of a solution in dilute ammonia. The crystals were extremely volatile, disappearing in a few minutes on exposure to the air at room temperature.

Enzyme Experiments. The rates of transamination in a leucine-pyruvate system, as measured by the formation of $\alpha$-ketoisocaproate, were approximately the same for tissues of the experimental and control cases. It was observed also that pyruvate gave rise to $\alpha$-ketoglutarate when these test media were incubated aerobically. While its initial rate of formation in the maple syrup urine case was much slower than that of the control the eventual concentration attained was considerably higher. This suggested further utilization in the control tissues, and this conclusion was borne out by the progressive appearance of succinate. No succinate was formed by tissues of the maple syrup urine case. 
Oxidative decarboxylation of $\alpha$-ketoisocaproate could not be detected in homogenates or slices of the experimental and control tissues. In a further control case, from which liver had been stored frozen for only one day, low activity was detected in homogenates. After storage for one week this activity had disappeared entirely. Using $\alpha$-ketoglutarate as substrate in these tests, carbon dioxide was produced by slices and homogenates of the control tissues, but not by those of the maple syrup urine case. This was of interest in view of the failure of the latter tissues to form succinate from pyruvate.

Experiments designed to show the possible formation of coenzyme $A$ intermediates of leucine metabolism below the level of $\alpha$-ketoisocaproate were unsuccessful in all cases. The substrates used were leucine-pyruvate, $\alpha$-ketoisocaproate, and isovaleryl-S-CoA, supplied with all known cofactor requirements.

\section{Discussion}

The most prominent feature of the aminoaciduria of maple syrup urine disease is the marked increase in the amounts of leucine, isoleucine and valine, and it is now well established that this results from high levels in the blood (Dancis et al., 1960). This suggests a block in the intermediary metabolism of these amino acids, and the demonstration by the above authors of normal transamination in a variety of tissues, and of the excretion of large amounts of the keto acid analogues of the branchedchain amino acids (Menkes, 1959), has indicated that the block occurs at a point below the keto acid level. These results have been confirmed in the present study.

Analyses of the urine and of tissue extracts have failed to detect the presence of free acid or coenzyme $A$ intermediates of further degradation beyond the keto acid stage, suggesting that the defect probably occurs in the oxidative decarboxylation of the keto acids. However, direct demonstration of a deficiency in this process has been prevented by the instability in storage of the enzyme systems concerned. Tests on fresh tissues, preferably obtained at biopsy, may be expected to provide a definite answer to this question when another patient becomes available for study. The above results are summarized in Fig. 1.

Some evidence of a more general failure of oxidative decarboxylation is seen in the apparent impairment of utilization of pyruvate and $\alpha$-ketoglutarate by tissue preparations. This situation could arise as the result of a primary defect in the oxidative decarboxylation of a specific keto acid,

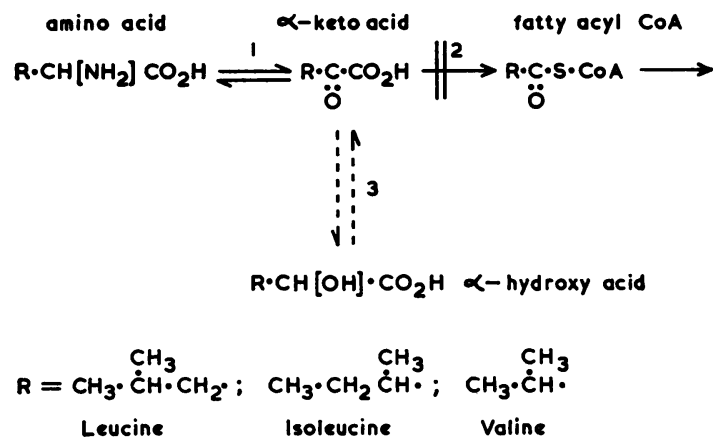

FIG. 1.-Initial steps in the degradation of the branched-chain amino acids. In maple syrup urine disease transamination (reaction 1) occurs normally, but further degradation is prevented by a block in oxidative decarboxylation (reaction 2). This causes the amino and $\alpha$-keto acids to accumulate, and gives rise to the $\alpha$-hydroxy acid by-products (reaction 3 )

which then affects similar processes by causing inhibition of some common mechanism. The high concentrations of the branched-chain keto acids may lead to varying degrees of competitive inhibition in this syndrome. In a wider sense, the consequences of such secondary effects may be more serious than those resulting directly from the primary anomaly. A generalized inhibition of oxidative decarboxylation would drastically disrupt the normal functioning of the citric acid cycle, and those tissues having high energy demands, e.g. brain, might be expected to suffer most from this limitation. In view of the early appearance of central nervous system symptoms in this disease, it would be of interest to determine whether the citric acid cycle is already affected at that stage, or whether this occurs only as a result of progressive complication. In this connexion it should be mentioned that previous authors have not reported a raised level of $\alpha$-ketoglutarate in the urine. Thus, the abnormal level found in this case may have reflected an episode of generalized metabolic failure of the kind outlined above.

The high concentrations of the $\alpha$-hydroxy acid analogues of the keto acids could also have a direct toxic influence, but again it is possible that secondary effects play an important part in neurochemical disturbances. For example, if the reductive process were normally coupled with oxidative decarboxylation in a DPN-linked system (as occurs in the coupled oxidation-reduction of pyruvate), then a failure by the oxidative process to regenerate reduced DPN could lead to interference in other similarly coupled systems.

However, the most obvious feature of the metabolic disturbance lies with the amino acids them- 
selves, and here the normal control of their intracellular distribution may be so deranged by the high local concentrations of leucine, isoleucine and valine, that tissue function becomes seriously impaired. Whatever might be the ultimate connexion between the biochemical lesion and the clinical symptoms, the only course of treatment suggested by the present biochemical studies is the dietary restriction of the branched-chain amino acids.

Work is proceeding in an attempt to identify the substances giving rise to the maple syrup odour. It may be found that such substances are members of a wider group of compounds possessing this characteristic odour, and being derived by similar processes from intermediary acids. Smith and Strang (1958) reported a case in which the urine had a penetrating odour resembling burnt sugar, and found this property to be associated with $\alpha$ hydroxy-butyric acid. They suggested that the odour was due to an oxidation or polymerization product of the hydroxy acid. Similar products could also be derived from the hydroxy acids occurring in maple syrup urine.

\section{Summary}

A case of maple syrup urine disease, with survival to 15 months, is presented. The urine contained high concentrations of leucine, isoleucine and valine, and of their respective keto acids, but other possible intermediates in the further degradation of these amino acids were not detected. The presence of the $\alpha$-hydroxy acid derivatives of the keto acids was confirmed.

A block in the metabolism of the three amino acids at the stage of oxidative decarboxylation is suggested by these results, but a direct demonstration of this was prevented by the instability of the enzyme systems in storage. Some indications of a more general failure of oxidative decarboxylation were observed, and the possible significance of this and the other anomalies is discussed.

I wish to express my thanks to Dr. Barbara Clayton for her advice and encouragement, and to $\mathrm{Mr}$. A. Whitfield for skilful technical assistance.

I am also grateful to Professor A. Moncrieff for permission to report this case, and to Professor C. E. Dent, Dr. M. Bodian and Dr. Barbara Ockenden for supplying experimental tissues.

\section{REFERENCES}

Coon, M. J., Robinson, W. G. and Bachhawat, B. K. (1955) In A Symposium on Amino Acid Metabolism, ed. McElroy, W. D. and Glass, H. B., p. 431. The Johns Hopkins Press, Baltimore.

Crome, L., Dutton, G. and Ross, C. F. (1961). Maple syrup urine disease. J. Path. Bact., 81, 379.

Dancis, J., Levitz, M., Miller, S. and Westall, R. G. (1959). Maple syrup urine disease. Brit. med. J., 1,91.

- 1 and Westall, R. G. (1960). Maple syrup urine disease Branched-chain keto-aciduria. Pediatrics, 25, 72.

Dent, C. E. and Westall, R. G. (1961). Studies in maple syrup urine disease. Arch. Dis. Childh., 36, 259.

El Hawary, M. F. S. and Thompson, R. H. S. (1953). Separation and estimation of blood keto acids by paper chromatography. Biochem. J., 53, 340 .

Lugg, J. W. H. and Overell, B. T. (1948). 'One'- and 'two-dimensional' partition chromatographic separations of organic acids on an inert sheet support. Aust. J. Sci. Res., A., 1, 98.

Mackenzie, D. Y. and Woolf, L. I. (1959). Maple syrup urine disease: an inborn error of the metabolism of valine, leucine and isoleucine associated with gross mental deficiency. Brit. med. J., 1, 90.

Menkes, J. H. (1959). Maple syrup disease: isolation and identification of organic acids in the urine. Pediatrics, 23, 348.

- Hurst, P. L. and Craig, J. M. (1954). A new syndrome: progressive familial infantile cerebral dysfunction associated with an unusual urinary substance. Ibid., 14, 462 .

Smith, A. J. and Strang, L. B. (1958). An inborn error of meta bolism with the urinary excretion of $\alpha$-hydroxy-butyric acid and bolism with the urinary excretion of $\alpha$-hydroxy-butt
phenylpyruvic acid. Arch. Dis. Childh., 33, 109.

Smith, I. (1958). Chromatographic Techniques, p. 186. Heinemann, London.

Stadtman, E. R. (1952). The net enzymatic synthesis of acetyl coenzyme A. J. biol. Chem., 196, 535.

Westall, R. G., Dancis, J. and Miller, S. (1957). Maple sugar urine disease. Amer. J. Dis. Child., 94, 571.

Whitfield, A. E. (1960). Diazotised p-nitroaniline as a location reagent for ammonium salts of aliphatic acids. J. Chromatog., 4,350 . 